\title{
Life meanings and environmentally responsible behavior due to the subjective comfort and satisfaction of drug addicts at the stage of rehabilitation
}

\author{
Pavel Ermakov ${ }^{1}$, Anna Kryuchkova ${ }^{2}$, Ekaterina Denisova, ${ }^{2,}$, and Anastasia Kolenova ${ }^{2}$ \\ ${ }^{1}$ Russian Scientific Center of the Russian Academy of Education, Southern Federal University, \\ 344006, Bolshaya Sadovaya str., 105/42, Rostov-on-Don, Russia \\ ${ }^{2}$ Don State Technical University, 344003, Gagarin Sq., 1, Rostov-on-Don, Russia
}

\begin{abstract}
The article presents the results of a study of life meanings and values in connection with the life satisfaction of persons with drug addiction at the stage of rehabilitation. The urgency of the problem is determined by the fact that the statistics provided by the UN confirm that the number of people who use drugs is steadily increasing every year. In this regard, the issues of prevention of drug addiction and rehabilitation of addicts for the Russian society are today the most acute and represent a global problem. The results obtained in the study state that for drug addicts at the stage of rehabilitation, they begin to have a meaningful attitude to their life, positively assess the life path they have passed and the experience gained, considering it the beginning of a new stage in life, and make plans for the future. This fact may indicate the productivity of the rehabilitation program. They do not think about how much life in general is subject to control on their part. The respondents attach value to the very living of life, feel the need to be able to feel love in all its manifestations. Status and altruistic meanings are of the least importance in the respondents' system of life meanings. Hedonistic meanings of life prevail, acceptance of life as it is. Also, statistically significant relationships were found between the components of life meanings and values and the components of life satisfaction in drug addicts.
\end{abstract}

\section{Introduction}

Chemical types of addiction are caused by substances that effect the circulation of endogenous neurotransmitters in the body, and physiological ones - directly affecting the nervous system. The nature of the impact in both cases has a neurochemical basis, affecting the human psyche [9]. When the body gets used to the regular exogenous intake of substances involved in metabolism, it reduces their endogenous production. This describes the mechanism of the formation of physiological dependence. When the use of a substance stops, there is a need for this substance to carry out basic physiological processes [3].

\footnotetext{
* Corresponding author: denisovakeith@gmail.com
} 
The psychological mechanism for the development of addiction is associated with pleasant sensations from substances that induce a person to repeat the experience of their use [6].

The factors contributing to the emergence and development of drug addiction are considered to be the subject of interdisciplinary research. We believe that the biopsychosocial model of addictive behavior is the most complete and multifaceted. The model emphasizes the equivalence of biological, social and psychological factors in the development of addictive behavior [4]. The last group of factors is of particular interest to us. The presence of hereditary burden or the negative influence of social factors is often not a direct risk factor in the formation of an addictive pattern. This is confirmed by numerous examples where individuals with a genetic predisposition had resistance to addictions of various forms [17].

Previous studies have shown that the effectiveness of therapy is often determined by personality characteristics $[15,16]$. In the development of chemical addiction, the peculiarities of its course and the prognosis of the results of rehabilitation, the personality characteristics of addicts also matter. A. Yu. Akopov considered a strong need for pleasure and amusement (a desire to consume and receive) to be an important psychological characteristic of an addict. He also argued that an addictive personality is characterized by compliance, malleability, susceptibility, willingness to surrender to any person, activity or a substance [1]. The concept of the addictive personality of V.D. Mendelevich seems to be interesting to us. Within the framework of this theory, it is substantiated that the central characteristic of a person prone to addictive behavior is infantilism, naivety, innocence, spontaneity, curiosity, striving for vivid impressions, egocentrism and fear of being abandoned are also characteristic [11]. I.N. Pyatnitskaya distinguished the psychological characteristics of addicts: indifference to social problems, lack of formed individual interests, aggressiveness towards society [13]. B.V. Zeigarnik noted the role of motive in the development of addiction and believed that as the addiction deepens, pathologically altered needs are formed. This is accompanied by a deformation of the hierarchy of motives [18]. However, the study of the psychological characteristics of a person who is prone or actively exhibiting addictive behavior is associated with certain difficulties. According to most studies the problem is that it is difficult to identify which psychological characteristics of the personality were the cause, and which - the consequence of dependence. At the same time, researching the psychological determinants of the propensity to addictive behavior is important, both in theoretical - methodological and practical aspects.

Recently, the study of life meanings and values of drug addicts has been gaining popularity in the field of social and psychological disciplines. Scientists agree that the vital activity of the individual as a whole, the level of its achievements are conditioned by the value-semantic structures $[1,7]$. D.A. Leontiev believes that the system of life meanings and values acts as a regulator of personality development, being a component of the worldview $[10,12]$. Insufficient development of the system of life meanings and personal values causes manifestations of subjective discomfort and "existential vacuum" [14]. Some researchers believe that chemical dependence determines a system of specific personal meanings, where a psychoactive substance acts as a meaning-forming value $[2,8]$. At the same time, under the influence of a narcotic drug, the system of personal meanings acquires a rigid, stable and fixed pattern, which leads to deficiency of personal resources [5, 8]. However, despite a fairly wide range of works in this area, the problem of helping people with drug addiction remains quite acute. The social need for effective assistance to addicted people and the lack of research into the relationship between the meanings of life, values and satisfaction with the life of people with drug addiction sparked our interest in this topic. 


\section{Research methods}

Purpose of our research: to study the meaning of life and value orientations in connection with the life satisfaction of persons with drug addiction.

The study involved drug addicts aged 17 to 60 years (74\% - men and $26 \%$ - women). The sample included respondents with incomplete Secondary (6.38\%), Secondary (29.79\%), further professional education (25.53\%), incomplete higher education $(4.26 \%)$ and higher education $(34.04 \%)$. All respondents were undergoing treatment in rehabilitation centers for drug addicts, with a remission period of 4 to 6 months. The sample size was 120 people.

To assess the general meaningfulness of life, its temporal perspective and the locus of personality control, we used the "Test of Life-Meaning Orientations», which is a Russianlanguage adaptation of D.A. Leontiev test "Purpose in Life" ("PIL") D. Krambo and L. Makholik. To interpret the results, the obtained data were compared with the normative indicators for the general meaningfulness of life and five studied subscales: 1) goals in life; 2) the process of life or interest and emotional richness of life; 3 ) the effectiveness of life or satisfaction with self-realization; 4) locus of control - I (I am the master of life); 5) locus of control - Life or controllability of life.

To study life meanings, we used the "Methodology for the study of the system of life meanings", developed by V.Yu. Kotlyakov in 2004 at the Kemerovo State University. This questionnaire analyzes an individual as altruistic, existential, hedonistic, status, selfrealization, communicative, family and cognitive meanings.

To study a person's attitude to the world, to other people, to himself and to determine the hiarircy of personal values, the "Value orientations" method (M. Rokich) was used. The methodological basis of the methodology is the theory of M. Rokich about dividing values into two classes: values of individual existence (terminal values or values-goals) and values of a mode of action (instrumental values or values-means). The research procedure assumes that the respondents rank two lists of values. The processing and interpretation of the results is based on the analysis of the subject's hierarchy of values.

To determine the general psychological state of a subjects, their psychological adaptation we used the "Life Satisfaction Index" methodology (B. Newgarten, adaptation by N. V. Panina) - Life Satisfaction Index A (LSIA) developed by Bernice Newgarten (Bernice L. Neugarten) and colleagues in 1961. Russian-language adaptation was made by N.V. Panina in 1993. The technique makes it possible to assess the general life satisfaction and five its components.

Data processing included standard methods of descriptive statistics, tests for normality of distribution; the results of which were applied nonparametric statistical methods of analysis: Spearman's rank correlation coefficient. For statistical processing of the empirically obtained data, we used standard licensed computer programs: "Microsoft Office" and "Statistica" version 13.

\section{Results}

Table 1 presents the results of studying the life-meaning orientations of the respondents, obtained using the "Test of life-meaning orientations" (DA Leontiev). 
Table 1. The results of the "Test of life-meaning orientations".

\begin{tabular}{|l|c|c|}
\hline \multicolumn{1}{|c|}{ Scales } & Average score & Standard deviation \\
\hline $\begin{array}{l}\text { Locus of Control- } \\
\text { Life }\end{array}$ & 25.45 & 6.57 \\
\hline Locus of control-I & 19.02 & 5.23 \\
\hline $\begin{array}{l}\text { General level of } \\
\text { meaningfulness in } \\
\text { life }\end{array}$ & 90.79 & 20.60 \\
\hline Life results & 22.51 & 6.19 \\
\hline Goals in life & 28.49 & 8.71 \\
\hline Life process & 26.74 & 7.71 \\
\hline
\end{tabular}

Evaluating the data obtained, we can say that all the components of the respondents' meaningful orientations, including the general level of meaningfulness of life, are at the lower border of the mean values, taking into account the standard deviation. In the sample as a whole, $30 \%$ of respondents have a level of general meaningfulness of life above average and $30 \%$ of respondents have an extremely low level of meaningfulness in life. These results indicate that the surveyed respondents, on the whole, have a rather meaningful attitude towards themselves and their lives. The standard deviation here has slightly larger values than in the given normative indicators, which indicates a greater degree of data fragmentation around the arithmetic mean, i.e. due to the fact that respondents have both different reasons for the onset of addiction and different periods of dependence and duration of treatment, they have different attitudes towards their life and, with different involvement, think about its goals, process and result, as well as about their own the ability to control your life.

To identify the structure of the respondents' meaningful orientations, the results obtained on five scales were converted into absolute values (Fig. 1).

\section{9}

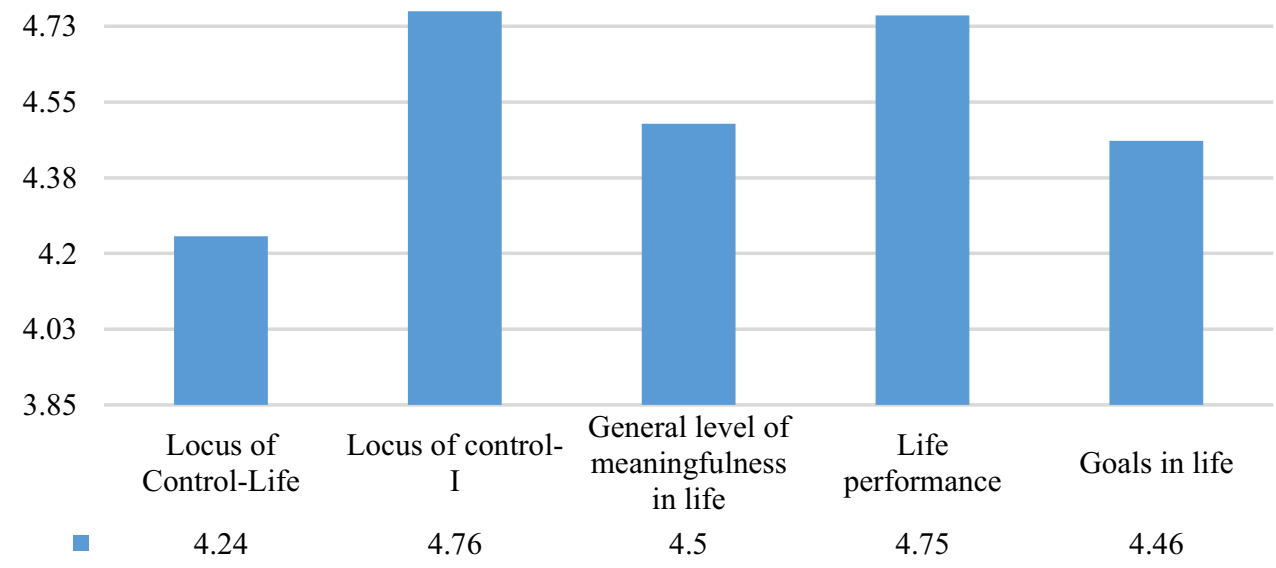

Fig. 1. The structure of life-meaning orientations, in absolute values.

As a result, the following structure of life-meaning orientations can be identified: Locus of control-I $\geq$ Goals in life $>$ Life results $>$ Life process $>$ Locus of Control-Life.

The obtained data show that for the respondents, the most important is the awareness of responsibility and control over their lives and the events that happen to them. The image of the future is also of great importance, the understanding that after rehabilitation they will have a "future" where they can achieve new results. They also quite positively assess the passed period of life, considering it a starting point from which they can make plans for the 
future. Least of all, respondents think about how much life in general is subject to their control.

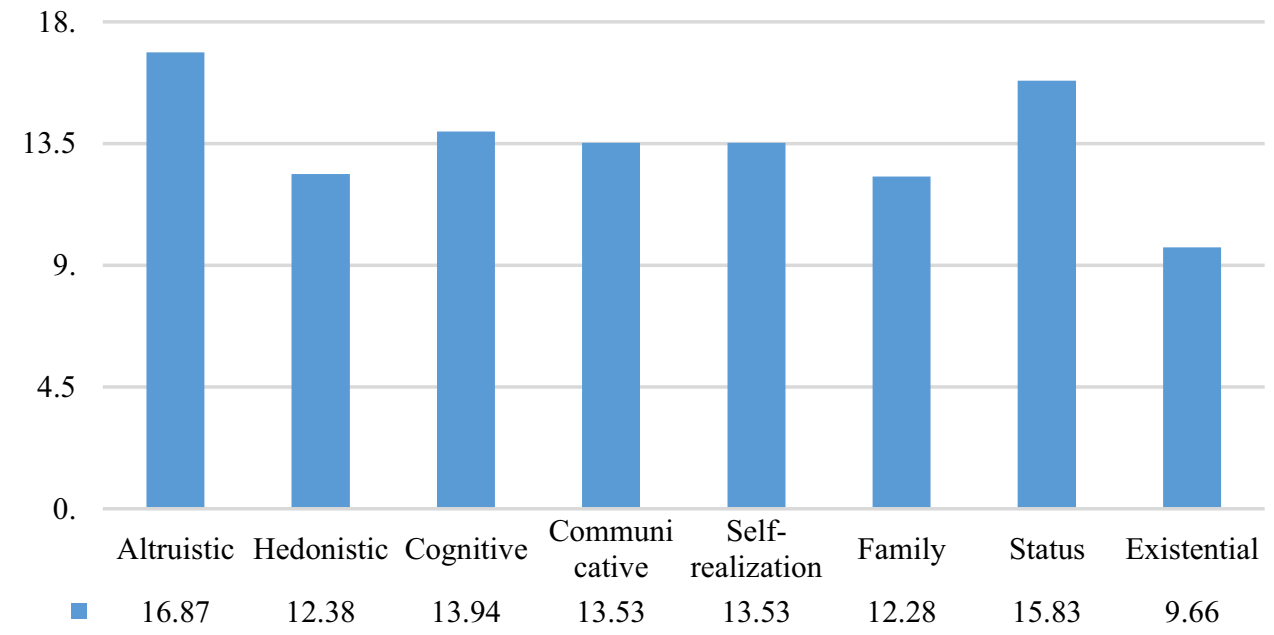

Fig. 2. Systems of life meanings, in the average scores.

The data obtained using the "Methodology for the study of the system of life meanings" (V.Yu. Kotlyakov) (Fig. 2) show that the categories of life meanings of the respondents belong to the level of average significance (10-17 points). In this case, it is necessary to note the following structure of the system of life meanings: Existential $>$ Family $>$ Hedonistic $>$ Self-realization $=$ Communicative $>$ Cognitive $>$ Status $>$ Altruistic.

The resulting structure of the system of life meanings indicates that the respondents express the importance of their existence, of living, having freedom of choice and experiencing love. They also highly value the support of close and dear people, there is a desire to take care of their family members and participate in their destiny. Despite the rather long addictive period, the majority of respondents highly value the experience of a variety of vivid emotions and sensations, enjoyment of life takes only the third place in their system of life meanings. Despite the rather long addictive period, the majority of respondents highly value the experience of a variety of vivid emotions and sensations, enjoyment of life takes only the third place in their system of life meanings. This fact may indicate the effectiveness of therapy and rehabilitation programs. Status and altruistic values are of the least importance in the system of life meanings of the respondents, which indicates that these people are quite indifferent to the society around them. On the one hand, they do not seek for a prestigious position, and, on the other hand, they do not express any particular desire to selflessly help other people.

The results concerning value orientations in addicts obtained using the "Value orientations" method (M. Rokich) are presented in Table 2.

Table 2. The results of the study of values: "Value orientations" (M. Rokich), ranks.

\begin{tabular}{|l|c|c|l|c|c|}
\hline Terminal values & $\begin{array}{c}\text { Sum of } \\
\text { ranks }\end{array}$ & $\begin{array}{c}\text { Average } \\
\text { rank }\end{array}$ & Instrumental values & $\begin{array}{c}\text { Sum of } \\
\text { ranks }\end{array}$ & $\begin{array}{c}\text { Average } \\
\text { rank }\end{array}$ \\
\hline Active life & $\mathbf{7 . 2 6}$ & $\mathbf{5}$ & Accuracy & 9.30 & 9 \\
\hline Life wisdom & $\mathbf{7 . 0 4}$ & $\mathbf{4}$ & Politeness & $\mathbf{7 . 2 6}$ & $\mathbf{3}$ \\
\hline Health & $\mathbf{5 . 7 4}$ & $\mathbf{1}$ & High requests & 13.30 & 17 \\
\hline Interesting job & 9.81 & 11 & Cheerfulness & $\mathbf{7 . 3 8}$ & $\mathbf{4}$ \\
\hline $\begin{array}{l}\text { The beauty of } \\
\text { nature and art }\end{array}$ & 13.23 & 17 & Diligence & 9.72 & 11 \\
\hline
\end{tabular}




\begin{tabular}{|l|c|c|l|c|c|}
\hline Love & $\mathbf{5 . 8 1}$ & $\mathbf{2}$ & Independence & $\mathbf{6 . 3 8}$ & $\mathbf{2}$ \\
\hline $\begin{array}{l}\text { Financially } \\
\text { secure life }\end{array}$ & 9.40 & 9 & $\begin{array}{l}\text { Intransigence to } \\
\text { shortcomings }\end{array}$ & 14.68 & 18 \\
\hline Having friends & 9.79 & 10 & Education & 9.38 & 10 \\
\hline Public acceptance & 12.00 & 15 & Responsibility & $\mathbf{8 . 3 8}$ & $\mathbf{5}$ \\
\hline Cognition & 10.23 & 13 & Rationalism & $\mathbf{8 . 7 7}$ & $\mathbf{6}$ \\
\hline Productive life & 8.64 & 8 & Self-control & 10.36 & 14 \\
\hline Development & 9.85 & 12 & Courage & 8.98 & 7 \\
\hline Entertainment & 11.96 & 14 & Firm will & 9.19 & 8 \\
\hline Liberty & 8.19 & 7 & Tolerance & 11.06 & 16 \\
\hline $\begin{array}{l}\text { Happy family } \\
\text { life }\end{array}$ & $\mathbf{7 . 6 6}$ & $\mathbf{6}$ & The breadth of views & 10.66 & 15 \\
\hline $\begin{array}{l}\text { The happiness of } \\
\text { others }\end{array}$ & 14.98 & 18 & Honesty & $\mathbf{6 . 0 4}$ & $\mathbf{1}$ \\
\hline Creation & 13.13 & 16 & Efficiency in business & 10.17 & 13 \\
\hline Self-confidence & $\mathbf{6 . 2 8}$ & $\mathbf{3}$ & Sensitivity & 9.98 & 12 \\
\hline
\end{tabular}

The resulting hierarchy of terminal values shows that the general, most significant values for these respondents are "health", "self-confidence", "love", "life wisdom", "active life" and "happy family life". The respondents considered the least significant values to be "happiness of others", "beauty of nature and art", "creativity", "public recognition", "entertainment" and "cognition". With regard to instrumental values (the means by which respondents are ready to achieve their goals), the following hierarchy is noted in terms of importance: "honesty", "independence", "good breeding", "cheerfulness", "responsibility" and "rationalism". The respondents give the least importance to such values-means as "intransigence to shortcomings in oneself and others", "high demands", "tolerance", "open-mindedness", "self-control" and "efficiency in business". The obtained distributions of the respondents' value orientations directly correlate and confirm the above-described structure of the system of life meanings.

The data obtained using the "Life Satisfaction Index" test (B. Newgarten, adaptation by N.V. Panina) are presented in Figure 3, indicate the low satisfaction of respondents with the system of attitudes towards various aspects of their lives. Since the basis of this indicator is the emotional component, we can say that the respondents are characterized by a high level of emotional tension and anxiety, low emotional stability, as well as dissatisfaction with the current situation and their role in it.

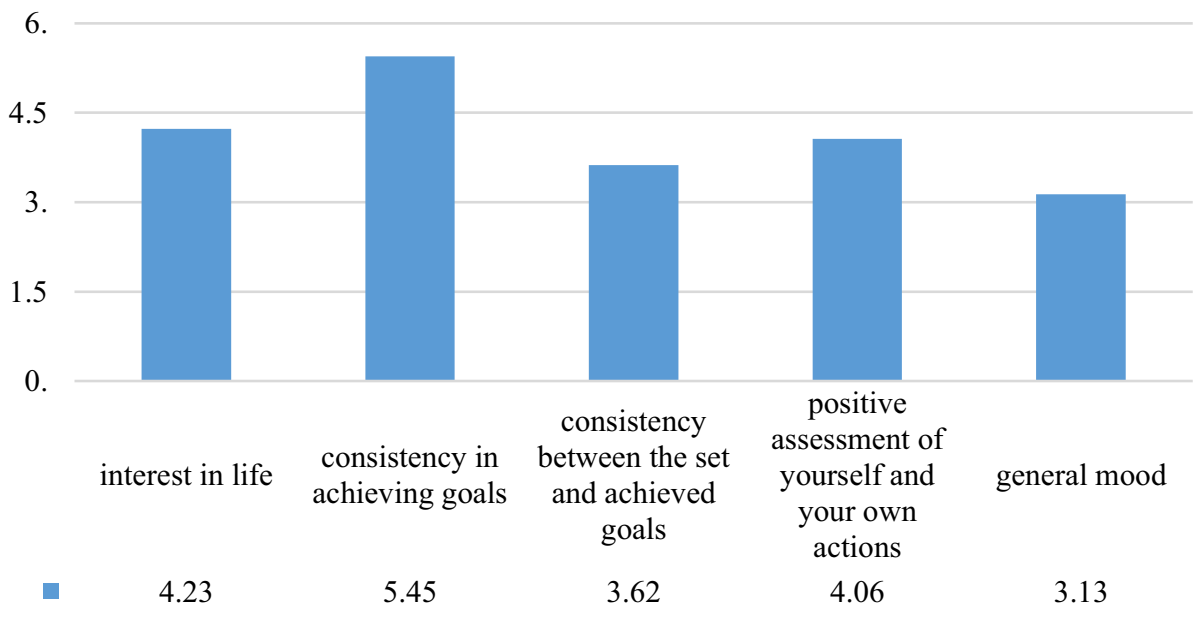

Fig. 2. The results of the study of life satisfaction, in the average scores. 
The resulting distribution is within the average standards. Nevertheless, it should be noted that the respondents are characterized by a low level of optimism, they lack pleasure in life. They also do not believe they are capable of achieving the goals they set for themselves. However, a fairly high score on the "Consistency in Achieving Goals" scale indicates such qualities of respondents as decisiveness, perseverance, and persistence in achieving goals.

As a result of the correlation analysis, direct and inverse relationships were found that have statistical significance between the studied components of life-meaning and value orientations and the components of life satisfaction in drug addicts: Life result \& General mood (significant negative correlation $(\mathrm{Rs}=-0.393 ; \mathrm{p}<0.001)$ ); Family meanings \& Positive assessment of oneself and one's own actions (significant positive correlation ( $\mathrm{Rs}=0.454 ; \mathrm{p}$ $<0.001)$ ); Cheerfulness \& Consistency between goals set and achieved (significant positive correlation $(\mathrm{Rs}=0.444 ; \mathrm{p}<0.001)$ ); Tolerance \& Positive assessment of oneself and one's own actions (significant positive correlation ( $\mathrm{Rs}=0.430 ; \mathrm{p}<0.001)$ ); Business values \& General mood (significant negative correlation (Rs $=-0.440 ; \mathrm{p}<0.001)$ ); Altruistic values $\&$ Positive assessment of oneself and own actions (significant positive correlation (Rs $=$ $0.382 ; \mathrm{p}<0.001)$ ).

\section{Conclusions}

Based on the empirical study of life-meanings and values in connection with the life satisfaction of drug addicts at the stage of rehabilitation, the following conclusions can be drawn: 1) Drug addicts at the stage of rehabilitation, in general, begin to have a meaningful attitude to their lives, positively assess the life path they have passed and the experience gained, considering it the beginning of a new stage in life, and make plans for the future. They do not think about how much life in general is subject to control on their part. 2) The respondents value most their existence, living, having freedom of choice and experiencing love. The least importants in the respondents' system of life meanings show status and altruistic meanings. Hedonistic meanings of life prevail with an acceptance of life as it is. Also, statistically significant correlations were found between the components of lifemeaning and value orientations and the components of life satisfaction.

\section{References}

1. A.Yu. Akopov, Freedom from addiction. Social diseases of personality (Rech, SPb, 2008)

2. S.V. Berezin, Drug addiction through the eyes of a family psychologist (Rech, SPb, (2005).

3. J.S. Brook, Genetic, Social and General Psychology Monographs 116(2), 111-264 (1990)

4. J. Draeger, The Pysician and Sportsmedicine 33(6), 13-23 (2005)

5. R. Garifullin, Transformation of semantic structures of a drug addicted person (Sfera, M., 2000)

6. M.D. Griffiths, Cyber Psychology \& Behavior 3(2), 211-218 (2000)

7. T.A. Klimontova, Theory and practice of social development 10, 158-160 (2013)

8. O.V. Koltsova, Therapy with drug addicts (Rech, SPb, 2007)

9. V.V. Kosonogov, E.V. Vorobyeva, E.M. Kovsh et al., International Journal of Cognitive Research in Science, Engineering and Education 7(1), 137-142 (2019) Doi: 10.5937 / ijcrsee1901137K 
10. D.A. Leontiev, The inner world of personality. Essay on the psychology of personality (M., 1993)

11. V.D. Mendelevich, Psychology of a dependent personality, or a teenager surrounded by temptations (Marevo, Yoshkar-Ola, 2002)

12. V. Pishchik, I. Li, Iinterpersona: an International journal on personal relationships 14(2), 137-149 (2020) https://doi.org/10.5964/ijpr.v14i2.3793

13. I.N. Pyatnitskaya, Teenage narcology (M., Medicine, 2002)

14. P.D. Shabanov, Psychology of drug addicts (SPb, 2002)

15. I.A. Skirtach, N.M. Klimova, A.G. Dunaev, V.A. Korkhova, SHS Web of Conferences. The conference proceedings Don State Technical Universyty 09011 (2019) https://doi.org/10.1051/shsconf/20197009011

16. I. Skirtach, E. Denisova, V. Korkhova, E3S Web of Conferences 210, 17007 (2020) https://doi.org/10.1051/e3sconf/202021017007

17. E.V. Vorobyeva, P.N. Ermakov, E.F. Borokhovski et al., F1000 Research 9, 446 (2020) https://doi.org/10.12688/f1000research.22503.2

18. B.V. Zeigarnik, Pathopsychology (Publishing house of Moscow University, M., 1986) 